\title{
CURRENT MACHINE LEARNING APPLICATIONS IN ACCOUNTING AND AUDITING
}

\author{
DOI: 10.17261/Pressacademia.2020.1337 \\ PAP- V.12-2020(1)-p.1-7
}

\section{Derya Ucoglu}

Istanbul Bilgi University, Business Administration Department, Istanbul, Turkey. derya.ucoglu@bilgi.edu.tr, ORCID: 0000-0001-5510-3574

\section{To cite this document}

Ucoglu, D. (2020). Current machine learning applications in accounting and auditing. PressAcademia Procedia (PAP), V.12, p.1-7

Permanent link to this document: $h$ ttp://doi.org/10.17261/Pressacademia.2020.1337

Copyright: Published by PressAcademia and limited licensed re-use rights only.

\begin{abstract}
Purpose- Machine learning is an area of computer science that learns from large amounts of data, identifies patterns, and makes predictions about future events. In the accounting and auditing professions, machine learning has been increasingly used in the last few years. Therefore, this study aims to review the current machine learning applications in accounting and auditing with a concentration on Big Four companies. Methodology- In this study, the machine learning tools and platforms developed by Big Four companies are examined by conducting a content analysis.

Findings- It has been identified that Big Four companies developed several machine learning tools that are used for consistent audit coordination and management, fully automated audits (only in certain areas, such as cash audit), data analysis, risk assessment, and extracting information from documents.

Conclusion- To benefit from the advantages, the Big Four companies are still expanding their portfolio of machine learning projects. On the other hand, the ethical problems and potential risks of security and violating privacy regulations by using machine learning applications in accounting and auditing should also be considered. This rapid transformation in the profession also creates a need for ethical and regulatory guidance and oversight for accounting and auditing companies.
\end{abstract}

Keywords: Machine learning, accounting, auditing, big four companies, artificial intelligence JEL Codes: M40, M41, M42

\section{INTRODUCTION}

The technological developments such as machine learning that enable processing data fast and without any errors or bias are widely employed in many different areas. Thus, the potential for machine learning algorithms to provide accountants and auditors with enhanced data analysis is accordingly high.

Machine learning tools designed by humans can perform many tasks that can help auditors and accountants. For instance, instead of sampling data, an entity's entire ledger may be audited with automation (Shimamoto, 2018).

In this study, the advantages and disadvantages of implementing machine learning techniques were identified through a literature review and by integrating insights from previous studies. The current machine learning technologies developed by Big Four accounting companies were examined and summarized.

\section{MACHINE LEARNING}

\subsection{Introduction to Machine Learning}

Machine learning is an area of computer science which studies learning computer algorithms that use statistics for determining patterns in huge amount of data and making accurate predictions for unknown future events. Machine learning techniques have been used in many different fields, such as education, health, biology, and finance (Dogan \& Birant, 2021, p.1).

In the 1930s, Thomas Ross worked on a machine that simulated a living creature's behavior, which can be considered the first study in the area. Thomas Ross and his professor Stevenson Smith developed a Robot Rat that can find the way through an artificial maze. Their study demonstrated methods to program a computer to behave like animals or human beings in the learning process (Bhavsar et al., 2017, Chapter 12, p.283). But the term "machine learning" was introduced by Arthur Samuel in 1959 and was defined as "a field of study that gives 
computers the ability to learn without being explicitly programmed". In 1997, Tom M. Mitchell provided a broader definition of machine learning as being concerned with developing computer programs that can automatically improve with experience. Both definitions included the idea of computers being able to learn patterns and trends from historical data and predict the future with accuracy by enhancing their learning performance. Machine learning aims to identify the model that provides the most repeatable and accurate prediction of future data. For that purpose, algorithms are deployed to construct mathematical models based on sample data (training data). Then the accuracy of the predictive ability of models is evaluated (testing data) (Cho et al., 2020, p.1).

Machine learning involves both general and domain knowledge. General knowledge is not dependent on the data or the task and is related to the basis of machine learning such as statistics, computer science, or neural science. On the other hand, domain knowledge is about the field of data like engineering, finance, health, or chemistry. Domain knowledge has an essential role in machine learning as it helps designing better datasets (Deng et al., 2020, p.2).

Since its first introduction, machine learning techniques became very popular and are currently used by many businesses. Based on previous viewings on a website, you may be suggested a book or a show that you may like, or your bank may inform you because of a suspicious transaction that does not fit your usual spending pattern (Ahmed, 2020, pp.2022-2023). These are some examples of machine learning applications that we face very often in our daily life. Machine learning can analyze many data points related to a given set of situations to determine which ones are relevant. Then it can apply the results to another similar set of data to predict the outcomes (Shimamoto, 2018).

In the following years, similar to many other areas, accounting and auditing will go through more significant changes due to machine learning, artificial intelligence, big data usage, blockchain, and other technological developments, and will be supported more by automation. (Türegün, 2019, p.91)

\subsection{Literature Review}

There are many studies in the literature about how to use machine learning techniques in accounting and auditing. The purposes and results of some of the studies are summarized below.

Anandarajan \& Anandarajan (1999) focused on comparing machine learning techniques for the going concern reporting of auditors. The results of the study showed that the artificial neural network model had a better predictive ability in determining the type of going concern audit report compared to expert systems and multiple discriminant analysis.

Kotsiantis et al. (2006) explored the effectiveness of machine learning techniques for identifying firms that presented fraudulent financial statements. They performed several experiments using representative learning algorithms and determined that the proposed stacking variant methodology achieved better than other methods.

Song et al. (2014) studied how to assess the financial statement fraud risk by applying machine learning methods. The experimental results obtained from implementing the back-propagation neural network, C5.0 decision tree, logistic regression, and support vector machine demonstrated that non-financial risk factors and a rule-based system provided lower error rates. Thus, they concluded that the proposed approach could decrease the financial risks of stakeholders.

In the study by Ding, Peng, and Wang (2019), K-medians clustering, a machine learning-based peer selection method, was employed to companies' key financial ratios related to specific research objectives. Based on the sample, including 598 bankruptcies and 48,536 nonbankrupt firm-year observations, the K-medians clustering technique was combined with material misstatement detection and bankruptcy prediction models. The study indicated that employing a machine learning technique contributed to enhancing the models by including information about K-medians clustering-based peer firms.

Lokanan and Tran (2019) used machine learning algorithms (a dynamic anomaly detection method) to detect any anomalies in the financial statements of Vietnamese listed firms by rating the creditworthiness of each firm's quarterly financial report. The findings showed that the model is capable of ranking quarterly financial reports in terms of creditworthiness. The implemented model also indicated that while the financial statements of most of the Vietnamese listed firms are trustworthy, about a quarter of them are highly questionable.

Lahann, Scheid \& Fettke (2019) researched machine learning techniques to show how they can be utilized to minimize risks and increase VAT compliance. In the study, real-world data set of a leading company in the chemical industry was exported from the company's ERP system. The results showed that machine learning algorithms could identify anomalies that would have led to compliance violations and offered promising opportunities to integrate tax compliance requirements into IT systems.

To predict fraud, Bao et al. (2020) proposed a model that used readily available raw financial data extracted from financial statements rather than calculated financial ratios. As a powerful machine learning tool, the ensemble learning method, which combines the predictions of a set of base estimators to improve the generalization ability and robustness, was applied. The results indicated that the ensemble learning model based on the 28 raw financial data items outperformed the Dechow et al. and Cecchini et al. models which were identified as a benchmark.

\section{ADVANTAGES AND DISADVANTAGES OF APPLYING MACHINE LEARNING TECHNIQUES}

Based on the review of prior literature, the advantages and disadvantages of implementing machine learning techniques in accounting and auditing are summarized below: 
Advantages:

- $\quad$ Consistency in decision-making

- $\quad$ Ability to process huge amounts of structured and unstructured data (ICAEW, p.6)

- $\quad$ Shorten the data processing cycle (IAA, 2017, p.3)

- Increased efficiency and effectiveness

- Error reduction and increased reliability of financial information (Zemankova, 2019, p.149)

- Models being continuously updated with less effort due to constant changes in fraud patterns (PwC, Machine learning: what every risk and compliance professional needs to know)

Disadvantages:

- Ethical problems

- $\quad$ Risk of bias and logical errors in the model design (IAA, 2017, p.3)

- Potential risks of security and violating privacy regulations (Alarcon, Fine \& Ng, 2019, pp.3-4)

- $\quad$ Need for a complete, well-balanced, and large dataset to assure prediction accuracy (Taniguchi, Sato \& Shirakawa, 2018, p.1)

- High cost of development

\section{CURRENT APPLICATIONS OF MACHINE LEARNING IN ACCOUNTING AND AUDITING}

Most of the accounting and auditing tasks have a mechanic and repetitive nature, making them suitable for machine learning applications. (Zemankova, 2019, p.149) Routine accounting processes such as accounts receivable and accounts payable management, preparation of expense reports, and risk assessment can easily be automated by machine learning. For instance, machine learning algorithms can match an invoice received with the related purchase order, determine the correct expense account for recognition, and place it in a payment pool where a human worker can examine and submit the payment request to the payment queue (Haq, Abatemarco \& Hoops, 2020, p.8)

Because of the advantages of implementing machine learning techniques, Big Four accounting firms have made massive investments in technological innovations and developed several platforms or tools that used machine learning and artificial intelligence algorithms (Kokina \& Davenport, 2017, p.116). In addition to these platforms and tools developed, there are smaller projects for accounting outsourcing services in which machine learning tools are employed for bookkeeping or tax declaration purposes.

As Big Four companies follow the latest innovations in the field of accounting and audit (Zemankova, 2019, p.151), the current applications of machine learning have been reviewed by focusing on the tools and technologies developed by Big Four:

\subsection{Earnst and Young (EY)}

Machine learning techniques are employed by EY to analyze and extract data from unstructured data to gain further audit evidence and to analyze large datasets for assessing material misstatement risks due to fraud. Machine learning applications increase the number of documents analyzed in addition to increased accuracy and speed.

Canvas: is the first online platform that connects audit professionals with their clients and enables consistent audit coordination and management regardless of size, location, or complexity. Canvas provides real-time monitoring of the audit and critical milestones in the audit process, quick customization of the audit approach due to the changes in the regulatory environment, and instant reporting of findings (EY, EY Canvas).

Helix: is a global analytics platform that is available to all audit teams and can handle data of any size and embed the analytical audit approach into the company's methodology. The platform analyzes journal entries, revenue and expenses, trade receivable and payable activities, inventory movements and records, assesses the riskiness of a client's mortgage portfolio, and identifies any hidden patterns, trends, and anomalies. By Helix, rather than spending their time on data collection, the auditors can focus on conducting a high-quality audit (EY, EY Helix).

Blockchain Analyzer: provides increased transparency on the blockchain transactions of clients as support to audit processes (EY, Audit Innovation).

\subsection{PwC}

GL.ai: is a revolutionary bot that uses machine learning algorithms to examine vast amounts of data such as uploaded transactions, the users, the amounts, and accounts in each transaction to identify potential errors or fraud without any bias. GL.ai is the first module of PwC's Audit.ai, and the other modules are being developed to enhance audit quality, efficiency, and client service (PwC, Harnessing the power of Al to transform the detection of fraud and error). 
Cash.ai: is a new tool that uses artificial intelligence and machine learning techniques to conduct a fully automated cash audit by analyzing cash balances, bank reconciliations and confirmation letters, foreign exchange and financial condition of the bank (PwC, Harnessing Al to pioneer new approaches to the audit).

Halo: is a data auditing technology that analyzes huge volumes of data and provides improved risk assessment. It highlights patterns and unusual relations and specifies high-risk transactions by graphical visualizations (PwC, The PwC Audit). "Halo for Employee Expenses" detects anomalies, aligns policies to reduce costs, and provides an accurate classification of expenses for tax purposes (PwC, Halo for Employee Expenses).

\subsection{Deloitte}

Argus: is Deloitte's first cognitive audit application that uses advanced machine learning techniques to identify and extract key financial information from electronic documents (Davenport, 2016, p.6). With the virtual eyes of Argus, instead of sampling, data extracted from the entire population can be used to determine potential risks, anomalies, and trends (Deloitte, Delivering smarter audits - Insights through innovation, 2017, p.6).

Cortex: is a cloud-based analytics application that was initially designed for audit and tax clients but now is also being used for consulting, risk, and financial advisory services. Cortex provides centralized data storage, big data management, advanced analytics, algorithms, models, and patterns (Deloitte, CortexAl).

Omnia DNAV: is a digital solution that revolutionizes the audit of securities and investments by combining digital technologies, machine learning, data science with auditor judgment to deliver high-quality audits. Omnia DNAV transforms client data and external vendor data to establish a new way of performing valuations using intelligent algorithms (Deloitte, Press releases).

Optix: provides advanced data analysis for large journal entry datasets to identify the transactions that can attract the interest of auditors (Deloitte, Delivering smarter audits - Insights through innovation, 2017, p.4).

Signal: is a risk analytics software that examines publicly available financial information to identify potential risks so that a comprehensive risk assessment can be provided to clients (Deloitte, Delivering smarter audits - Insights through innovation, 2017, p.4). By Signal, the audit teams can identify potential risks of failure, material misstatement, and other risk factors (Deloitte Signal, Empowers more informed risk assessment, 2018, p.1).

Reveal: is a tool to test account balances and identify relationships for providing predictive modeling that can help auditors identify particular areas of audit interest (Deloitte, Delivering smarter audits - Insights through innovation, 2017, p.4).

Sonar: is a tool that helps to check quickly and accurately the information entered by humans, such as a client database containing product description, the VAT rate for each product, commodity code, the barcode, and any other necessary information and identifies labeling errors in databases (Deloitte, 16 Artificial Intelligence projects from Deloitte - Practical cases of applied Al, 2018, pp.14-15).

GRAPA (Guided Risk Assessment Personal Assistant): works as an assistant for determining a risk strategy based on the pooled expertise of all auditors. By GRAPA, it is possible to mark out the chosen risk strategy by an auditor against all other strategies that have been used in previous audits (Deloitte, 16 Artificial Intelligence projects from Deloitte - Practical cases of applied Al, 2018, pp.18-19).

HR Agent Edgy: is a cognitive chatbot that can interact with employees and potential candidates. Besides, Edgy can resolve employee queries, assist employees with submitting expense claims, record the sickness reports of employees, or match candidates to a current vacant position (Deloitte, 16 Artificial Intelligence projects from Deloitte - Practical cases of applied Al, 2018, pp.24-25).

DocQMiner: is a machine learning application specifically developed for contract analysis. Concerning the provisions of IFRS 16 , all lease contracts should be listed on the balance sheet. By DocQMiner, it is possible to extract the relevant information (i.e., the start date of the contract) from those contracts (Deloitte, 16 Artificial Intelligence projects from Deloitte - Practical cases of applied Al, 2018, p.31).

Eagle Eye: is a tool designed to search the internet for identifying whether a company is likely to encounter financial distress soon. Traditional monitoring systems review financial statements, credit transfers, or bank accounts. On the other hand, Eagle Eye looks for early warning signals by collecting vast volumes of data, analyzing and correlating them, and recognizing specific patterns before the financial statementbased distress indicators are observed (Deloitte, 16 Artificial Intelligence projects from Deloitte - Practical cases of applied Al, 2018, p.32).

BrainSpace: is a self-learning tool used to assist in legal cases. BrainSpace uses machine learning and cluster analysis to search through unstructured data to identify what can be used as evidence for supporting the client's defense. It also provides visually appealing formats for presenting the relevant data (Deloitte, 16 Artificial Intelligence projects from Deloitte - Practical cases of applied Al, 2018, p.38).

\subsection{KPMG}

Clara: is a smart audit platform that adopts the latest machine learning and artificial intelligence solutions to analyze data, provide meaningful patterns, and identify risks and anomalies (KPMG, KPMG Clara).

The following table summarizes some of the tools and platforms developed by Big Four companies based on their initial application area. 
Table 1: Platforms/Tools Developed by Big Four Accounting Companies

\begin{tabular}{|l|c|c|c|c|}
\cline { 2 - 5 } \multicolumn{1}{c|}{} & EY & PwC & Deloitte & KPMG \\
\hline \multirow{4}{*}{ Tax \& Legal } & & & Sonar & \\
\hline \multirow{4}{*}{ Audit } & Canvas & GL.ai & Argus & Clara \\
\cline { 2 - 5 } & Helix & Cash.ai & Optix & \\
\cline { 2 - 5 } & Blockchain Analyzer & Halo & Signal & \\
\cline { 2 - 5 } & & & Cortex & \\
\cline { 2 - 5 } & & & Reveal & \\
\cline { 2 - 5 } & & & Omnia DNAV & \\
\hline Consulting & & & GRAPA & \\
\hline \multirow{2}{*}{ Risk Advisory } & & & DocQMent Edgy & \\
\hline Financial Advisory & & & Eagle Eye & \\
\hline
\end{tabular}

The Digital Accountancy Forum \& Awards is a prestigious event organized by International Accounting Bulletin since 2012. Deloitte and PwC won the last six awards for the "Audit Innovation of the Year" at the Digital Accountancy Forum \& Awards, which shows the interest of Big Four companies in technological innovations.

Table 2: The Digital Accountancy Forum \& Awards of International Accounting Bulletin - Audit Innovation of the Year

\begin{tabular}{|c|c|c|}
\hline Year & Award Winner & Innovation \\
\hline 2015 & Deloitte & Argus \\
\hline 2016 & PwC & Halo \\
\hline 2017 & PwC & GL.ai \\
\hline 2018 & Deloitte & Cortex \\
\hline 2019 & PwC & Cash.ai \\
\hline 2020 & Deloitte & Omnia DNAV \\
\hline
\end{tabular}

http://www.internationalaccountingbulletin.com/events-archive

As examined, it seems that Big Four accounting companies have already developed several platforms or tools concerning machine learning algorithms and have integrated them into their audit and consultancy processes. Due to heavy competition and the advantages of implementing such technologies, it appears that these companies will employ more automation in the following years (Faggella, 2020).

\section{CONCLUSION}

The new technologies, such as machine learning, gave rise to different ways of accomplishing tasks, which also affected the accountancy and auditing professions. Despite the drawbacks, implementing machine learning tools has many advantages, such as increased efficiency and effectiveness by faster data analysis, high-quality audit, error reduction, early identification of risks, and creating a competitive advantage. Therefore, the Big Four companies have developed various tools and are still expanding their portfolio of machine learning projects.

There are projections that $30 \%$ of corporate audits will be performed by machine learning and artificial intelligence platforms by 2025 . This rapid transformation in the profession also creates a need for ethical governance in terms of implementation. Additionally, regulatory guidance and oversight are also required concerning machine learning and artificial intelligence tools used in the processes by accounting and auditing companies (Munoko, Brown-Liburd \& Vasarhelyi, 2020, p.2).

\section{REFERENCES}

Ahmed, A. (2020). "From Data to Wisdom" Using Machine Learning Capabilities in Accounting and Finance Professionals. Talent Development \& Excellence, 12(3), 2019-2036.

Alarcon, J. L., Fine, T. \& Ng, C. (2019). Accounting Al and Machine Learning: Applications and Challenges. Pennsylvania CPA Journal, 2019 Special Issue, 1-5.

Anandarajan, M. \& Anandarajan, A. (1999). A comparison of machine learning techniques with a qualitative response model for auditor's going concern reporting. Expert Systems with Applications, (16), 385-392.

Bao, Y., Ke, B., Li, B., Yu, J. \& Zhang, J. (2020). Detecting Accounting Fraud in Publicly Traded U.S. Firms Using a Machine Learning Approach. Journal of Accounting Research, 58(1), 199-235. 
Bhavsar, P., Safro, I., Bouaynaya, N., Polikar, R. \& Dera, D. (2017). Machine Learning in Transportation Data Analytics. In M. Chowdhury, A. Apon, \& K. Dey (Eds.), Data Analytics for Intelligent Transportation Systems (pp. 283-307). Elsevier Inc.

Cho, S., Vasarhelyi, M. A., Sun, T., \& Zhang, C. (2020). Learning from Machine Learning in Accounting and Assurance. Journal of Emerging Technologies in Accounting, 17(1), 1-10.

Davenport, T. H. (2016). Deloitte - The power of advanced audit analytics. Retrieved from https://www2.deloitte.com/content/dam/Deloitte/us/Documents/deloitte-analytics/us-da-advanced-audit-analytics.pdf (Accessed: 6 Oct. 2020).

Deloitte (2018). 16 Artificial Intelligence projects from Deloitte - Practical cases of applied Al. Retrieved from https://www2.deloitte.com/content/dam/Deloitte/nl/Documents/innovatie/deloitte-nl-innovatie-artificial-intelligence-16-practicalcases.pdf (Accessed: 7 Oct. 2020).

Deloitte, CortexAl. Retrieved from https://www2.deloitte.com/us/en/pages/consulting/topics/cortex-ai-platform.html (Accessed: 10 Oct. 2020).

Deloitte (2017). Delivering smarter audits - Insights through innovation. Retrieved from https://www2.deloitte.com/content/dam/Deloitte/us/Documents/audit/us-audit-smarter-audits-dynamic-insights-through-innovation.pdf (Accessed: 6 Oct. 2020).

Deloitte (2018). Deloitte Signal. Retrieved from https://www2.deloitte.com/content/dam/Deloitte/cn/Documents/audit/deloitte-cn-auditinnovation-product-intro-deloitte-signal-en-191119.pdf (Accessed: 10 Oct. 2020).

Deloitte, Press releases - . Deloitte Wins 2020 'Audit Innovation of the Year' at the Digital Accountancy Forum \& Awards. Retrieved from https://www2.deloitte.com/us/en/pages/about-deloitte/articles/press-releases/deloitte-wins-2020-audit-innovation-of-the-year-atdigital-accountancy-forum-awards.html (Accessed: 24 Oct. 2020).

Deng, C., Ji, X., Rainey, C., Zhang, J. \& Lu, W. (2020). Integrating Machine Learning with Human Knowledge. iScience, 1-46 (Journal Pre-proof). https://doi.org/10.1016/j.isci.2020.101656.

Ding, K., Peng, X., \& Wang, Y. (2019). A Machine Learning-Based Peer Selection Method with Financial Ratios. Accounting Horizons, 33(3), 7587.

Dogan, A. \& Birant, D. (2021). Machine learning and data mining in manufacturing. Expert Systems with Applications, (166), 1-22.

EY, Audit Innovation. Retrieved from https://www.ey.com/en_gl/audit/innovation (Accessed: 21 Oct. 2020)

EY Canvas. Retrieved from https://www.ey.com/en_gl/audit/technology/canvas (Accessed: 21 Oct. 2020).

EY Helix. Retrieved from https://www.ey.com/en_gl/audit/technology/helix (Accessed: 21 Oct. 2020).

Faggella, D. (2020). Al in the Accounting Big Four - Comparing Deloitte, PwC, KPMG, and EY. Retrieved from https://emerj.com/ai-sectoroverviews/ai-in-the-accounting-big-four-comparing-deloitte-pwc-kpmg-and-ey/ (Accessed: 8 Oct. 2020).

Haq, I., Abatemarco, M. \& Hoops, J. (2020). The Development of Machine Learning and its Implications for Public Accounting. CPA Journal, 90(6), 6-9.

ICAEW (2018). Artificial intelligence and the future of accountancy. Retrieved from https://www.icaew.com//media/corporate/files/technical/information-technology/thought-leadership/artificial-intelligence-report.ashx?la=en (Accessed: 22 Oct. 2020).

IIA. (2017). Küresel Bakış Açıları ve Anlayışlar: Yapay Zeka - İç Denetim Mesleğine İlişkin Dikkate Alınması Gerekenler, Kısım I. Retrieved from https://www.tide.org.tr/file/documents/pdf/GPAI-Artificial-Intelligence-Part-I-Revised.pdf (Accessed: 2 Sept. 2020).

International Accounting Bulletin, Events Archive. Retrieved from http://www.internationalaccountingbulletin.com/events-archive (Accessed: 20 Oct. 2020).

Kokina, J. \& Davenport, T. H. (2017). The Emergence of Artificial Intelligence: How Automation is Changing Auditing, Journal of Emerging Technologies in Accounting, 14(1), 115-122.

Kotsiantis, S., Koumanakos, E., Tzelepis, D. \& Tampakas, V. (2006). Forecasting Fraudulent Financial Statements using Data Mining, International Journal of Computational Intelligence, 3(2), 104-110.

KPMG Clara. Retrieved from https://home.kpmg/xx/en/home/services/audit/kpmg-clara.html (Accessed: 18 Oct. 2020)

Lahann, J., Scheid, M. \& Fettke, P. (2019). Utilizing Machine Learning Techniques to Reveal VAT Compliance Violations in Accounting Data. 2019 IEEE 21st Conference on Business Informatics (CBI), 1-10.

Lokanan, M. \& Tran, V. (2019). Detecting anomalies in financial statements using machine learning algorithm The case of Vietnamese listed firms. Asian Journal of Accounting Research, 4(2), 181-201. 
Munoko, I., Brown-Liburd, H. L. \& Vasarhelyi, M. (2020). The Ethical Implications of Using Artificial Intelligence in Auditing. Journal of Business Ethics, 1-26.

PwC, Halo for Employee Expenses. Retrieved from https://www.pwc.com/us/en/services/tax/tax-innovation/halo-for-employeeexpenses.html (Accessed: 15 Oct. 2020).

PwC, Harnessing Al to pioneer new approaches to the audit. Retrieved from https://www.pwc.com/gx/en/about/stories-from-across-theworld/harnessing-ai-to-pioneer-new-approaches-to-the-audit.html (Accessed: 15 Oct. 2020).

PwC, Harnessing the power of Al to transform the detection of fraud and error. Retrieved from https://www.pwc.com/gx/en/about/storiesfrom-across-the-world/harnessing-the-power-of-ai-to-transform-the-detection-of-fraud-and-error.html (Accessed: 15 Oct. 2020$).$

PwC, Machine learning: what every risk and compliance professional needs to know. Retrieved from https://www.pwc.com/us/en/services/forensics/library/machine-learning-risk-compliance.html (Accessed: 15 Oct. 2020).

PwC, The PwC Audit. Retrieved from https://www.pwc.com/gx/en/services/audit-assurance/the-pwc-audit.html (Accessed: 15 Oct. 2020).

Shimamoto, D. C. (2018). Why Accountants Must Embrace Machine Learning. Retrieved from https://www.ifac.org/knowledgegateway/preparing-future-ready-professionals/discussion/why-accountants-must-embrace-machine-learning (Accessed: 24 Sept. 2020).

Song, X., Hu, Z., Du, J. \& Sheng, Z. (2014). Application of Machine Learning Methods to Risk Assessment of Financial Statement Fraud: Evidence from China. Journal of Forecasting, (33), 611-626.

Taniguchi, H., Sato, H. \& Shirakawa, T. (2018). A machine learning model with human cognitive biases capable of learning from small and biased datasets. Scientific Reports, (8), 1-13.

Türegün, N. (2019). Impact of technology in financial reporting: The case of Amazon Go. Journal of Corporate Accounting \& Finance, 30(3), 90-95.

Zemankova, A. (2019). Artificial Intelligence in Audit and Accounting: Development, Current Trends, Opportunities and Threats - Literature Review. 2019 International Conference on Control, Artificial Intelligence, Robotics \& Optimization (ICCAIRO), 148-154. 